
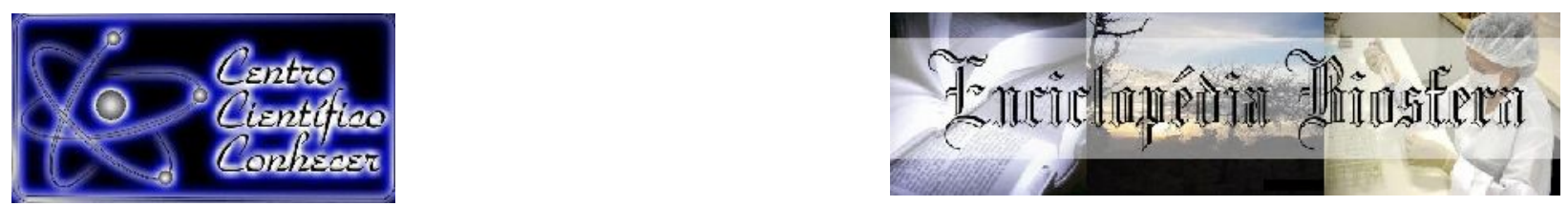

\title{
BISCOITO TIPO COOKIE DE FARINHA DE AMÊNDOA DE PEQUI: AVALIAÇÃO FÍSICA E QUÍMICA
}

\author{
Stephany Ritucci da Silva ${ }^{1}$, Ellen Godinho Pinto ${ }^{2,}$ Dayana Soares ${ }^{3}$ \\ ${ }^{1}$ Graduanda em Tecnologia em Alimentos do Instituto Federal Goiano Campus \\ Morrinhos (stephany_ritucci@hotmail.com; ellen.godinho@ifgoiano.edu.br) \\ ${ }^{2}$ Professora Mestre do Instituto Federal Goiano - Campus Morrinhos \\ 3 Professora Mestre do Instituto Federal Goiano - Campus Morrinhos \\ Recebido em: 06/04/2018 - Aprovado em: 10/06/2018 - Publicado em: 20/06/2018 \\ DOI: 10.18677/EnciBio_2018A120
}

\begin{abstract}
RESUMO
O pequi (Caryocar brasiliense Camb) é uma planta originária do bioma cerrado, vegetação característica das Regiões: Nordeste, Centro Oeste e Norte de Minas Gerais. O mesocarpo do pequi possui alto valor comercial, porém são descartados no ambiente como resíduo: o endocarpo, e consequentemente a amêndoa, deixando assim de agregar mais valor a este fruto. A amêndoa do fruto do pequizeiro possui uma composição que é rica em riboflavina, tiamina, provitamina A e óleos que lhe confere grande valor nutritivo. São escassas as pesquisas que utilizam a amêndoa do pequi, seja na elaboração de novos produtos ou como subingrediente. Neste trabalho teve-se como objetivo desenvolver uma formulação de cookie com isenção de glúten, enriquecido com $10 \%$ de amêndoa de pequi, agregando valor aos produtos da cadeia produtiva do pequi e apresentando mais uma opção para os celíacos, além de avaliar as características: físico e químicas da amêndoa in natura, da farinha de amêndoa e o cookie enriquecido de farinha de amêndoa de pequi. Os biscoitos tipo cookie enriquecidos se caracterizaram como alimentos free glúten, e as avaliações físicas e químicas, mantiveram-se dentro dos padrões preconizados pela legislação.
\end{abstract}

PALAVRAS-CHAVE: cerrado, caryocar brasiliense camb, free glúten

\section{BISCUIT COOKIE TYPE OF PEQUI ALMOND FLOUR: PHYSICAL AND CHEMICAL EVALUATION}

\begin{abstract}
The pequi (Caryocar brasiliense Camb) is a plant native to the cerrado biome, the vegetation characteristics of the Regions: Northeast, midwest, and Northern Minas Gerais. The mesocarp of pequi has a high commercial value, but are discarded in the environment as residue the endocarpo, and consequently almond, and thus add more value to this fruit. The almond of the fruit of the pequi tree becomes has a composition that is rich in riboflavin, thiamine, provitamin A and oils which gives it great nutritional value. The mesocarp of pequi has a high commercial value, but are discarded in the environment as residue the endocarpo, and consequently almond, and thus add more value to this fruit. The almond of the fruit of the pequi tree becomes has a composition that is rich in riboflavin, thiamine, provitamin $A$
\end{abstract}


and oils which gives it great nutritional value.There is a lack of research that use the almond of pequi, is the development of new products or as subingrediente. This work had as objective to develop a formulation of cookie free of gluten, enriched with $10 \%$ of the almond of pequi, adding value to the products of the productive chain of pequi and presenting more choice to the celiac, in addition to evaluating the physical characteristics and chemical of the almond in nature, of almond flour and the cookie enriched flour almond of pequi. The biscuits type cookie enriched if characterized as a food free of gluten, and the evaluations of the physical and chemical, remained within the standards recommended by the legislation.

KEYWORDS: Caryocar brasiliense Camb, Closed, Free gluten

\section{INTRODUÇÃO}

O pequizeiro (Caryocar brasiliense Camb. - Caryocaraceae) é uma frutífera nativa do cerrado brasileiro, cujos frutos, são explorados de forma extrativista, é notória a importância econômica e nutricional, sendo intitulado de "ouro do cerrado" (MACHADO et al., 2013). O fruto do pequizeiro possui em seu interior uma amêndoa comestível pouco explorada, e na maioria das vezes descartadas no meio ambiente, desprezando assim a amêndoa que consequentemente pode ser ingredientes ou subingredientes para qualquer área da culinária, gerando alternativas econômicas para as indústrias e sustentabilidade ao meio ambiente (CARVALHO, 2007).

O Brasil ocupa a posição de segundo maior produtor mundial de biscoitos, entretanto o biscoito ocupa segundo lugar na mesa da população na primeira refeição do dia, o café da manhã, perdendo apenas para o pão. Os biscoitos têm ampla aceitação, consumidos por pessoas de qualquer faixa etária, sobretudo as crianças (ABIMAPI, 2017).

De acordo com a Resolução RDC no 263 de setembro de 2005, biscoitos são oriundos da mistura de farinha, amido e ou fécula com outros ingredientes, realizando processos de amassamento e cocção, fermentados ou não. Podem apresentar diversos tipos de cobertura, recheio, formato e textura diversos (BRASIL, 2005).

Os biscoitos tipo cookie, tem as características peculiares, possuem crocância referente a massa que leva menos líquido se comparado com outros biscoitos e a modulagem (GISSLEN, 2014). Os biscoitos tipo cookie podem ser reformulados por farinha isentas de glúten, tornando-se assim uma opção para pessoas que possuem alergia e/ou intolerância à proteína gliadina, contida no glúten (RAHAIE et al., 2014).

Através deste contexto, objetivou-se desenvolver uma formulação de cookie com isenção de glúten, enriquecido com a amêndoa do pequi, agregando valor aos produtos da cadeia produtiva do pequi e apresentando mais uma opção para os celíacos, além de avaliar as características físicas e químicas da amêndoa in natura, da farinha de amêndoa e o cookie enriquecido de farinha de amêndoa de pequi.

\section{MATERIAL E MÉTODOS}

As matérias-primas foram adquiridas no comércio local do município de Morrinhos- GO, com exceção dos pequis que foram obtidos por meio de coleta direta no cerrado do município de Morrinhos-GO, safra temporona 2017. Para a formulação do biscoito tipo cookie foi adotada a metodologia empregada por Silva et al. (2014), com adaptações. Desenvolvimento do cookie e as análises físicas e 
químicas na amêndoa in natura, farinha da amêndoa e o cookie de farinha de amêndoa de pequi foram realizados no Instituto Federal Goiano - Campus Morrinhos, nos Laboratórios de Panificação e de Análise de Alimento.

A obtenção da farinha da amêndoa de pequi foi obtida através da extração da amêndoa de pequi cortando o endocarpo com o auxílio de uma faca, martelo e tábua, em seguida foram dispostas em bandejas sendo estes levados para uma estufa com circulação forçada de ar a $70^{\circ} \mathrm{C} \pm 2^{\circ} \mathrm{C}$ por 24 horas para retirada de umidade. Posteriormente, as amêndoas foram trituradas com 0 auxílio do liquidificador até a obtenção da farinha de amêndoa de pequi.

A massa do biscoito tipo cookie foi obtida com a mistura de todos os ingredientes manualmente até a homogeneização. A Tabela 1 apresenta a formulação do biscoito tipo cookie enriquecida com farinha de amêndoa de pequi.

TABELA 1. Formulação do biscoito tipo cookie enriquecida com farinha de amêndoa de pequi

\begin{tabular}{lc}
\hline Matérias-primas & Porcentagem (\%) \\
\hline Fubá & 46,0 \\
Farinha de amêndoa de Pequi & 10,0 \\
Açúcar & 15,0 \\
Manteiga & 16,8 \\
Fermento & 01,2 \\
Sal & 01,0 \\
Água & 10,0 \\
\hline
\end{tabular}

Fonte: Autores (2017).

A moldagem foi feita manualmente seguindo um padrão de espessura 9,00 $\mathrm{mm}$ e tamanho $4,90 \mathrm{~mm}$. Os cookies foram analisados biometricamente antes e depois do forneamento, quanto ao peso (grama), espessura $(\mathrm{mm})$ e diâmetro $(\mathrm{mm})$, sendo o diâmetro e a espessura dos biscoitos medidos com paquímetro (Figura 1) e o peso obtido pela balança analítica, conforme descritos no método 10-50D da American Association of Cereal Chemists (AACC1). O fator de expansão foi calculado pela razão entre o diâmetro e a espessura dos biscoitos após 0 forneamento.

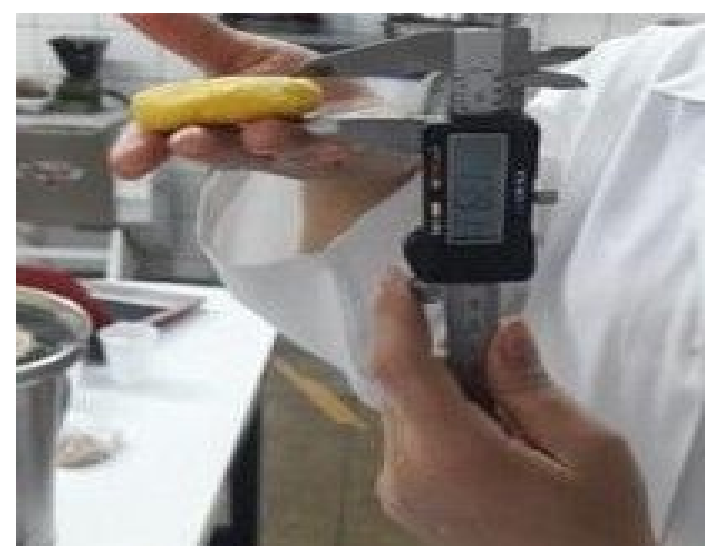

FIGURA 1: Espessura do cookie antes do forneamento.

Fonte: Autores (2018) 
No final, os cookies foram todos levados ao forno industrial, para a cocção, por um tempo de 20 minutos sob $200^{\circ} \mathrm{C} \pm 2^{\circ} \mathrm{C}$.

\section{Análises físicas e químicas}

A amêndoa de pequi in natura, farinha da amêndoa de pequi e o cookie foram submetidos às análises de: umidade, cinzas, $\mathrm{pH}$, acidez titulável, sólidos solúveis totais (SST), açúcares redutores, compostos fenólicos totais, vitamina C, proteína e teor de glúten, foram realizadas segundo metodologia do IAL (2008). Já as análises de proteína, cor, atividade de água $(A w)$ e análise de força de ruptura (textura - parâmetro utilizado foi velocidade $2 \mathrm{~mm} \cdot \mathrm{s}^{-1 \mathrm{n}}$ e distância $9 \mathrm{~mm}$ ), foram realizadas somente no biscoito tipo cookie, e as demais análises segundo as instruções de cada equipamento.

As análises de cor foram realizadas segundo o sistema "CIELAB" (CIE $\left.L^{*} a^{*} b^{*}\right)$, espaço de cor comumente utilizado para determinações de cor em alimentos. A partir desses dados foram calculados os valores de croma $\left(c^{\star}\right)$, que correspondem à saturação ou intensidade da cor (Eq. 1):

$$
c^{*}=\sqrt{ }\left(a^{2}+b^{2}\right) \text { Eq. } 1
$$

Foram calculados também os valores de ângulo de tonalidade (ângulo $h^{\circ}$ ), expressa em graus, pela Eq. 2:

$$
h^{*}=\operatorname{tang}^{-1}\left(b^{*} / a^{*}\right) \quad \text { Eq. } 2
$$

As análises foram conduzidas em triplicata e as análises biométricas foram realizadas em 10 cookies, sendo escolhidos de forma aleatória. Os dados foram tratados pela análise de variância (ANOVA), sendo as médias comparadas entre si pelo teste de Tukey, ao nível de $5 \%$ de significância, utilizando o programa ASSISTAT, versão 7,7.

\section{RESULTADOS E DISCUSSÃO}

Os resultados físicos e químicos na amêndoa in natura, farinha da amêndoa e o cookie de farinha de amêndoa de pequi estão apresentados na Tabela 2. apresentando grande variabilidade, quando comparados com dados da literatura, entretanto são considerados alguns fatores para essa variabilidade como: safra temporona, solo, clima, manuseio ou equipamentos, fatores que podem influenciar nos dados ao comparar com os da literatura.

TABELA 2. Resultados físicos e químicos das amêndoas de pequi (Caryocar brasiliense Camb.) in natura, farinha das amêndoas de pequi e cookies enriquecido de farinha de amêndoas de pequi.

\begin{tabular}{c|c|c|c}
\hline \multicolumn{4}{c}{ Amostras } \\
\hline Parâmetros & In natura & Farinha & Cookie \\
\hline Umidade (\% b.u) & $53,829 \pm 0,777^{\mathrm{a}}$ & $5,510 \pm 1,215^{\mathrm{b}}$ & $1,637 \pm 0,223^{\mathrm{c}}$ \\
\hline Cinzas (\%) & $1,967 \pm 0,468^{\mathrm{b}}$ & $5,416 \pm 0,117^{\mathrm{a}}$ & $1,926 \pm 0,169^{\mathrm{b}}$ \\
\hline pH & $6,266 \mathrm{a} \pm 0,044^{\mathrm{b}}$ & $6,200 \pm 0^{\mathrm{b}}$ & $6,300 \pm 0^{\mathrm{a}}$ \\
\hline $\begin{array}{c}\text { Acidez (\% de ácido } \\
\text { citrico) }\end{array}$ & $0,2613 \pm 0,027^{\mathrm{b}}$ & $0,6902 \pm 0,062^{\mathrm{a}}$ & $0,228 \pm 0,006^{\mathrm{b}}$ \\
\hline $\begin{array}{c}\text { SST ( } \text { Brix) } \\
\text { Açucares redutores } \\
\text { (g/100g) }\end{array}$ & $3,333 \pm 0,444^{\mathrm{c}}$ & $12,000 \pm 0^{\mathrm{b}}$ & $36,600 \pm 1,133^{\mathrm{a}}$ \\
\hline $\begin{array}{c}\text { Fenólicos totais } \\
\text { (mg AGE/100g) }\end{array}$ & $0,364 \pm 0,006^{\mathrm{c}}$ & $0,480 \pm 0,006^{\mathrm{a}}$ & $0,390 \pm 0,008^{\mathrm{b}}$ \\
\hline $\begin{array}{c}\text { Vitamina C (mg/100g } \\
\text { de ácido ascórbico) }\end{array}$ & $43,670 \pm 1,074^{\mathrm{a}}$ & $33,310 \pm 1,999^{\mathrm{b}}$ & $8,456 \pm 0,177^{\mathrm{c}}$ \\
\hline
\end{tabular}




\begin{tabular}{c|c|c|c}
\hline Aw & $N A$ & $N A$ & $0,572 \pm 0,004$ \\
\hline Proteína $\mathbf{( g / 1 0 0 g )}$ & $N A$ & $N A$ & $8,008 \pm 0,003$ \\
\hline Força de ruptura (N) & $N A$ & $N A$ & $180,960 \pm 8,560$ \\
\hline Glúten $\mathbf{( m / m )}$ & 0,0 & 0,0 & 0,0 \\
\hline
\end{tabular}

${ }^{*} N A=$ Não avaliado

As letras minúsculas diferentes em uma mesma linha, apresentam diferença estatística entre si pelo teste de Tukey $(p<0,05)$ pelo programa ASSISTAT (vs 7,7$)$.

A umidade encontrada nas amêndoas in natura foi de $53,8 \%$ e na farinha da amêndoa de pequi $5,5 \%$, quando comparada com a legislação está dentro dos padrões de umidade de outras farinhas, uma vez que não se tem ainda na legislação uma especificação para farinha de amêndoa de pequi. A umidade da farinha da amêndoa de pequi foi menor (RAHAIE et al. 2014) diferença esta que pode ser explicada pela diferença de solo, clima, colheita do fruto ou até mesmo na torrefação. No entanto a diferença na umidade das amêndoas in natura comparado com a farinha reduziu-se devido à evaporação oriunda do processo de torrefação, processo este que reduziu a quantidade de água nas amêndoas.

O teor de umidade do cookie foi de $1,6 \%$, os valores de umidade estão dentro do máximo que a legislação permite que é 14\% (BRASIL, 2005). Altos valores de umidade também são responsáveis pela redução da crocância, um atributo sensorial importante nos cookies (GUIMARÃES; SILVA, 2009).

Houve diferença significativa no valor obtido de cinzas na farinha de amêndoas de pequi $(5,1 \%)$, e na amêndoa in natura $(1,9 \%)$, tais valores ocorreram em função da redução da umidade na farinha de amêndoas de pequi, levando assim a concentração de diversos compostos químicos. A literatura confirma que a presença de minerais de interesse como: cálcio, ferro, zinco, selênio, fósforo, magnésio e outros, são indicados para a população que apresentem deficiência em minerais (MARIN et al., 2009). Observa-se na Tabela 2, que os biscoitos tipo cookies obtiveram 1,9\% de cinzas, o que atende a legislação que rege que para biscoitos doce a quantidade máxima de cinzas permitida é 3\% (BRASIL, 2005).

Não houve diferença significativa entre a farinha da amêndoa de pequi e a amêndoa in natura. $O$ cookie apresentou $\mathrm{pH}$ próximo da neutralidade. Esta característica é inerente a frutos desse grupo, visto que o $\mathrm{pH}$ da amêndoa de baru, segundo Almeida (1998), é de 6,11. Nos cookies as análises de pH foi de 6,30, o que determina um produto neutro, sendo um fator determinante, especialmente no sabor.

A acidez da amêndoa de pequi in natura foi de $0,2 \%$ e a farinha de amêndoas de pequi apresentou 0,6\%. Marques et al. (2015) encontraram em amêndoas de baru índices de acidez entre 0,30 a 0,41\%, valores similares ao deste estudo. Nos cookies a análise de acidez revelou 0,23\%. Em estudo de Pereira et al. (2016) encontraram de 0,41 a 0,88\% ao elaborarem e caracterizarem biscoitos tipo cookies amanteigados elaborados com farinha de jatobá. Para biscoitos, a legislação por meio da resolução CNNPA n.12 de 1978, estabelece o teor de acidez no máximo de 2,0\% (BRASIL, 1978).

Nos resultados de SST houve diferença significativa entre a amêndoa de pequi in natura $\left(3,33^{\circ} \mathrm{Brix}\right)$ e na farinha de amêndoa de pequi $\left(12^{\circ} \mathrm{Brix}\right)$. De acordo com Andrade et al. (2010) as amêndoas de baru apresentaram ${ }^{\circ}$ Brix de 12. Segundo Aquino et al. (2010) em estudos com biscoitos tipo cookies elaborados com farinha de resíduos de acerola, os SST ${ }^{\circ}$ Brix foi de $36,6^{\circ}$.

Ribeiro et al. (2012) avaliaram frutos do cerrado e estes apresentaram 
elevados teores de açúcares representados pelos sólidos solúveis totais. Entretanto, Santos et al. (2010) encontraram valores inferiores para a polpa de pequi in natura $(3,7 \mathrm{~g} 100 \mathrm{~g})$ e na desidratada $(3,5 \mathrm{~g} 100 \mathrm{~g})$. Já neste estudo foi obtido $4,66 \mathrm{~g} 100 \mathrm{~g}$ das amêndoas de pequi in natura, $15,13 \mathrm{~g} 100 \mathrm{~g}$ na farinha de amêndoas de pequi e nos cookies 20,86 g 100g.

Os teores de fenólicos totais apresentaram diferença significativa, na amêndoa de pequi in natura foi $0,37 \mathrm{mg}$ AGE $100 \mathrm{~g}$, na farinha de amêndoa de pequi foi $0,5 \mathrm{mg}$ AGE $100 \mathrm{~g}$ e nos cookies foram encontrados $0,4 \mathrm{mg}$ AGE $100 \mathrm{~g}$ de fenólicos, podendo se inferir, de acordo com esses resultados que são valores significativamente baixos se comparados com outros produtos. Os teores fenólicos encontrados foram inferiores aos observados por Roesler et al. (2007) quando analisaram também a amêndoa do ouro do cerrado (pequi) e obtiveram 1,59 mg AGE 100g. Os valores encontrados no presente estudo foram diferentes de Roesler et al. (2007), podendo ter interferência por características edafoclimáticas.

A quantidade de vitamina $C$ da amêndoa de pequi in natura foi superior 43,6 $\mathrm{mg} 100 \mathrm{~g}$ de ácido ascórbico a da amêndoa que foi $33,3 \mathrm{mg} 100 \mathrm{~g}$ de ácido ascórbico, isso ocorreu devido a vitamina $\mathrm{C}$ ser degradada com a temperatura. Freitas e Naves (2010) obtiveram 78,7 mg 100g de ácido ascórbico, concentração essa superior a encontrada na presente pesquisa em pequi. Entretanto, ao comparar os teores de vitamina $\mathrm{C}$ do pequi com outros frutos do cerrado, como o jenipapo (2,7 mg 100g), gabiroba (21,0 mg 100g), Mangaba (26,0 mg 100g), araticum $(34,0 \mathrm{mg} 100 \mathrm{~g})$ e cagaita $(8,4 \mathrm{mg} 100 \mathrm{~g})$ observou-se que a amêndoa do pequi, in natura ou torrada apresenta maior concentração da vitamina $C$ (FREITAS; NAVES , 2010). Nesta pesquisa obteve-se o teor de vitamina C de 8,4 mg $100 \mathrm{~g}$ de ácido ascórbico no cookie de amêndoa de pequi. Segundo a Resolução RDC $n^{\circ} 269$, de setembro de 2005, o consumo diário de vitamina C para crianças de 4 a 10 anos é de $45 \mathrm{mg}$ e para adultos é de $60 \mathrm{mg}$. O cookie enriquecido com farinha de amêndoa de pequi pode ser uma opção para a ingestão necessária de vitamina $\mathrm{C}$, sabendo-se que o ácido ascórbico possui ampla cadeia de benefícios.

A atividade de água encontrada no cookie de farinha de amêndoa de pequi foi acima de $0,5_{\mathrm{Aw}}$, dentro do padrão descrito por Clerici et al. (2013) para Aw de biscoito, que deve ser inferior a 0,6 $6_{A w}$. De acordo com Jardim (2010), mudanças físicas, como a crocância de biscoitos, dependem significativamente deste parâmetro. O teor de proteína encontrado nesta pesquisa no cookie de farinha de amêndoa de pequi foi de $8 \mathrm{~g} / 100 \mathrm{~g}$, Silva et al. (2014) em trabalho realizado com biscoito tipo cookie de amêndoa de pequi observaram teor de proteína de 9,89 $\mathrm{g} / 100 \mathrm{~g}$.

A força de ruptura do cookie apresentada neste trabalho foi acima dos valores encontrados por Moraes et al. (2010) em cookies com diferentes teores de açucares e por Clerici et al. (2013) em cookie obtido com farinha de gergelim desengordurada. Porém, não existe nenhum valor padrão para a força de ruptura de biscoito, mas sabe-se que este parâmetro é importante na qualidade do biscoito, afetando diretamente a aceitação pelos consumidores e as vendas (MORAES et al., 2010).

A análise de glúten na amêndoa de pequi caracterizou-se como isenta. Sendo, portanto, também negativa no cookie de farinha de amêndoa de pequi. Para o cookie foram feitas a determinações de cores, a Tabela 3 mostra os resultados obtidos, que podem ser influenciados pelos açúcares presentes e 0 tempo de cocção dos cookies. 
TABELA 3. Parâmetros de cor no cookie enriquecido com farinha de amêndoa de pequi, Sistema CIE L*A*B*.

\begin{tabular}{l|l|l|l|l|l}
\hline Parâmetros & $\boldsymbol{a}^{*}$ & $\boldsymbol{b}^{*}$ & $\boldsymbol{L}^{*}$ & $\boldsymbol{C}^{*}$ & $\boldsymbol{h}^{*}$ \\
\hline $\begin{array}{l}\text { Antes da } \\
\text { Cocção }\end{array}$ & $9,6 \pm 0,35$ & $52,8 \pm 1,04$ & $47,5 \pm 1,38$ & $53,66 \pm 0,98$ & $88,55 \pm 0,58$ \\
\hline $\begin{array}{l}\text { Depois da } \\
\text { Cocção }\end{array}$ & $13,5 \pm 1,42$ & $52,0 \pm 1,75$ & $46,5 \pm 3,68$ & $53,34 \pm 1,29$ & $83,83 \pm 2,26$ \\
\hline
\end{tabular}

Fonte: Autores (2017)

Observando os dados da Tabela 3, as coordenadas $a^{*}$ e $b^{*}$ expressam a variação de cor das amostras entre verde e vermelho $\left(-a^{*} e+a^{*}\right)$ e entre azul e amarelo $\left(-b^{*}\right.$ e $\left.+b^{*}\right)$, no presente estudo observou-se que as amostras apresentaram os parâmetros $a^{*} e b^{*}$ positivos, indicando as tendências das amostras a coloração amarelo e vermelho.

Os cookies antes do forneamento apresentaram valor de luminosidade superior a luminosidade dos cookies após forneamento. Quanto maior o valor da coordenada $L^{*}$ mais próxima ao branco a amostra está, com isso, pode-se dizer que os cookies antes do forneamento apresentaram colocação mais clara.

A tonalidade $\left(\mathrm{h}^{*}\right)$ grandeza que caracteriza a qualidade da cor, observada nos cookies antes do forneamento de $88,55 \pm 0,58$ e após o forneamento de $83,83 \pm 2,26$ indicam que as amostras apresentaram cor amarela. A saturação $\left(C^{*}\right)$, que representa pureza de cor, $53,66 \pm 0,98$ antes do forneamento e $53,34 \pm 1,29$ após o forneamento indica que os cookies antes do forneamento apresentaram coloração amarela mais forte que os cookies pós forneamento. $O$ índice croma foi fortemente influenciado pelos valores $b^{*}$ seguindo a mesma tendência que estes.

$\mathrm{Na}$ Tabela 4, o forneamento do cookie teve uma perda aproximada de $2 \mathrm{~g}$ do peso da massa inicial. Fasolin et al. (2007) observaram em cookie de farinha de banana uma perda de aproximadamente 1,5 g, Já Moraes et al. (2010) obtiveram uma menor perda, aproximadamente $1 \mathrm{~g}$. A perda de massa é esperada, pois 0 forneamento elimina água livre do produto.

TABELA 4. Características físicas dos cookies enriquecidos de farinha de amêndoa de pequi.

\begin{tabular}{l|c|c|c|c}
\hline \multicolumn{1}{c|}{ Amostras } & $\begin{array}{c}\text { Peso da } \\
\text { massa (g) }\end{array}$ & $\begin{array}{c}\text { Diâmetro } \\
(\mathbf{m m})\end{array}$ & $\begin{array}{c}\text { Espessura } \\
(\mathbf{m m})\end{array}$ & $\begin{array}{c}\text { Fator de } \\
\text { expansão }\end{array}$ \\
\hline $\begin{array}{l}\text { Antes da } \\
\text { Cocção }\end{array}$ & $24,000 \pm 0,915$ & $4,890 \pm 0,252$ & $9,020 \pm 0,830$ & - \\
\hline $\begin{array}{l}\text { Depois da } \\
\text { Cocção }\end{array}$ & $21,940 \pm 0,817$ & $6,150 \pm 0,210$ & $14,610 \pm 0,780$ & $0,42 \pm 0,107$ \\
\hline Diferença & $-2,060$ & $+1,260$ & $+5,590$ & - \\
\hline
\end{tabular}

Fonte: Autores (2017).

O diâmetro do cookie após o forneamento apresentou um aumento de aproximadamente 1,26 mm, segundo Moraes et al. (2010) os biscoitos geralmente apresentam aumento no diâmetro depois do forneamento, que é atribuído ao baixo conteúdo de glúten e força da farinha de trigo mole, que forma um filme frágil ao invés de rede viscoelástica. A espessura também teve um aumento significativo de $5,59 \mathrm{~mm}$, este fator está interligado ao aumento da espessura. 
O fator de expansão encontrado neste trabalho foi de 0,42 , ficando próximo aos encontrados por Moraes et al. (2010). Segundo Rasper (1991) biscoitos com fator de expansão muito alto ou muito baixo causam problemas na indústria, resultando em produtos com tamanho pequeno ou peso muito elevado.

\section{CONCLUSÕES}

A farinha de amêndoa de pequi apresentou teores de minerais, proteína, acidez, sólidos solúveis totais, açucares redutores e fenólicos totais maiores na farinha da amêndoa do pequi se comparada a amêndoa in natura. A farinha de amêndoa de pequi apresentou boa agregação e adaptação a massa do cookie, sendo confirmado com os parâmetros físicos e químicos no cookie de farinha de amêndoa de pequi.

Com esse estudo pode-se dizer que o pequi e seus subprodutos, tais como a amêndoa de pequi, possuem excelentes propriedades nutricionais, podendo ser utilizada sem perdas de qualidade na formulação de cookies, além disso, contribui para um maior valor agregado ao pequi e consequentemente aproveita um subproduto descartado na natureza.

\section{REFERÊNCIAS}

ABIMAPI- Associação Brasileira das Indústrias de Biscoitos, Massas Alimentícias e Pães \& Bolos Industrializados. Disponível em:< https://www.abimapi.com.br/>. Acesso em: 19 de abril de 2017.

AQUINO, A., C., M., S.; MOES, R., S.; LEAO, K., M., M.; FIGUEIREDO, A., V., D.; CASTRO, A., A. Avaliação físico-química e aceitação sensorial de biscoitos tipo cookies elaborados com farinha de resíduos de acerola. Revista Instituto Adolfo Lutz. São Paulo, v.69, n.3, p.379-86, $2010 . \quad$ Disponível: http://periodicos.ses.sp.bvs.br/pdf/rial/v69n3/v69n3a15.pdf.

ALMEIDA, S. P. Frutas nativas do Cerrado: caracterização físico-química e fonte potencial de nutrientes. In: SANO, S. M.; ALMEIDA, S. P. Cerrado: ambiente e flora. Planaltina: EMBRAPA - CPAC, 1998. 556 p.

ANDRADE, N., V.; MARIA, V., S.; VIEIRA, G.; RODRIGUES, C., S.; VERÔNICA, P., D.; KELLY, G., M., S. Características físico-químicas da amêndoa de macaúba e seu aproveitamento na elaboração de barras de cereais. Revista Alimento Nutritivo. Araraquara v.21, n.1, p. 79-86, 2010. Disponível: http://servbib.fcfar.unesp.br/seer/index.php/alimentos/article/viewArticle/1392.

BRASIL. Resolução RDC $\mathbf{n}^{\circ}$ 263, de 22 de setembro de 2005. Regulamento técnico para misturas para o preparo de alimento e alimentos pronto para o consumo. Disponível em: <http://www.anvisa.gov.br/alimentos/legis/especifica/regutec>. Acesso em: 24 de Agosto 2017.

BRASIL. Ministério da Saúde. Agência nacional de Vigilância Sanitária. Resolução CNNPA. $n^{\circ} 12$ de 24 de Julho de 1978. Padrões de Identidade e Qualidade para alimentos e Bebidas. Diário Oficial da União, Brasília, DF, 27 jul. 1978.

CARVALHO, I. S. H. Potenciais e limitações do uso sustentável da biodiversidade do Cerrado: um estudo de caso da Cooperativa Grande Sertão 
no Norte de Minas. Dissertação (Mestrado em Desenvolvimento Sustentável) Universidade de Brasília, Brasília, 2007.

CLERICI, M. T. P.; OLIVEIRA, M. E.; NABESHIMA, E. H. Qualidade física, química e sensorial de biscoitos tipo cookies elaborados com a substituição parcial da farinha de trigo por farinha desengordurada de gergelim. Brazilian Journal of Food Technology, Campinas, v. 16, n. 2, p. 139-146, 2013. Disponível: http://www.scielo.br/scielo.php?pid=S1981-

67232013000200008\&script=sci_abstract\&tlng=pt.

FASOLIN, L. H.; ALMEIDA, G. C.; CASTANHO, P. S.; NETTO OLIVEIRA, E. R.Biscoitos produzidos com farinha de banana: avaliações química, física e sensorial. Ciência e Tecnologia de Alimentos, Campinas, v. 27, n. 3, p. 524-529, 2007. Disponível: http://www.scielo.br/pdf/cta/v27n3/a16v27n3.pdf

FREITAS, J. B.; NAVES, M. M. Composição química de nozes e sementes comestíveis e sua relação com a nutrição e saúde. Revista de Nutrição. Campinas, v. 23, n. 2, p. 269- 279, 2010. Disponível: http://www.scielo.br/scielo.php?pid=S1415$52732010000200010 \&$ script=sci_abstract\&tlng=pt

IAL, INSTITUTO ADOLFO LUTZ, Métodos físico-químicos para análise de alimentos. 4 ed. São Paulo, 2008. 1018p.

GISSLEN, W. Panificação \& Confeitaria Profissionais. Le Cordon Bleu. Academia de Artes Culinárias de Paris. 5 ed. Barueri: Manole, 2014.

GUIMARÃES, M. M.; SILVA, M. S. Qualidade nutricional e aceitabilidade de barras de cereais adicionadas de frutos de murici-passa. Revista do Instituto Adolfo Lutz, São Paulo, v.68, n.3, p.426-433, 2009. Disponível http://periodicos.ses.sp.bvs.br/pdf/rial/v68n3/v68n3a15.pdf

JARDIM, D. C. P. Atividade de água e a estabilidade dos alimentos. In: MOURA, S. C. S. R.; GERMER, S. P. M. (Coord.). Reações de Transformação e Vida-deprateleira de Alimentos Processados. 4. ed. Campinas: ITAL, 2010. p. 17-23. (Manual Técnico, n. 6).

MARIN, A. M. F.; SIQUEIRA, E. M. A.; ARRUDA, S. F. Minerals, phytic acid and tannin contents of 18 fruits from the Brazilian savanna. International Journal of Food Sciences and Nutrition, Abingdon, v. 60, n.7, p. 180-190, 2009. Disponível: https://www.tandfonline.com/doi/abs/10.1080/09637480902789342.

MACHADO, M. T. C.; MELLO, B. C. B. S.; HUBINGER, M. D. Study of alcoholic and aqueous extraction of pequi (Caryocar brasiliense Camb.) natural antioxidants and extracts concentration by nanofiltration. Journal of Food Engineering, Essex, v. 117, n. 4,4 p. 450-457, $2013 . \quad$ Disponível: https://www.sciencedirect.com/science/article/pii/S0260877412005912.

MARQUES, F., NETO, J., CUNHA, L., PAULA, J., \& BARA, M. Identificação de terpenos e fitoesteróis nas sementes oleaginosas Dipteryx alata (baru). Revista Brasileira de Farmacognosia, v.25, n.5, p. 522-525, 2015. Disponível: 
https://revistas.ufg.br/REF/article/viewFile/35961/pdf.

MORAES, K. S.; ZAVAREZE, E. R.; MIRANDA, M. Z.; SALAS-MELLADO, M., L., M. Avaliação tecnológica de biscoitos tipo cookie com variações nos teores de lipídio e de açúcar. Ciência e Tecnologia de Alimentos, Campinas, v.30, n.supl.1, p. 233242, 2010.Disponível: http://www.scielo.br/pdf/cta/v30s1/36.pdf.

PEREIRA, M. M.; OLIVEIRA, E. N. A.; ALMEIDA, F. L. C.; FEITOSA, R. M. Processamento e caracterização físico-química de biscoitos amanteigados elaborados com farinha de jatobá. Revista Brasileira de Tecnologia Agroindustrial,

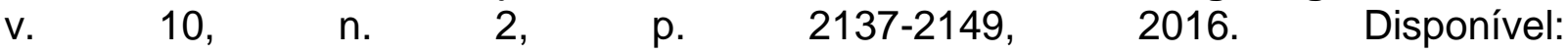
https://periodicos.utfpr.edu.br/rbta/article/view/3905.

RAHAIE, S.; GHARIBZAHEDI, S. M. T.; RAZAVI, S. H.; JAFARI, S. M. Desenvolvimentos recentes sobre novas formulações baseadas em ingredientes nutrientes para a produção de pão saudável-funcional: uma revisão. Journal of Food Science and Technology, Mysore, v. 51, n. 11, p. 2896-2906, 2014.Disponível: http://www.scielo.br/pdf/bjtt/v17n4/1981-6723-bjft-17-4-259.pdf.

RASPER, V. F. Quality evaluation of cereal and cereal products. In: LORENZ, K. J.; KULP, K. (Eds.). Handbook of cereal science and technology. New York: Marcel Dekker, 1991. p. 595-638.

RIBEIRO, M. C.; MARIANO, R. G. de B.; COURI, S.; FREITAS, S. P. Influence of the extraction method and storage time on the physicochemical properties and carotenoid levels of pequi (Caryocar brasilienseCamb.) oil. Ciência e Tecnologia de Alimentos,

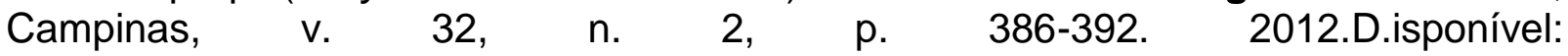
http://www.scielo.br/scielo.php?script=sci_arttext\&pid=S0101-20612012000200027

ROESLER, R.; CARRASCO, L. C.; HOLANDA, R. B. Atividade antioxidante de frutas do cerrado. Ciência e Tecnologia de Alimentos, v. 27, n. 1, p. 53-60, 2007. Disponível: $\quad$ http://www.scielo.br/scielo.php?script=sci_arttext\&pid=S010120612007000100010.

SANTOS, P.; PORTO, A. G.; SILVA, F.S. Avaliação físico-química e sensorial do pequi (caryocar brasiliensis Camb.) submetido à desidratação. Revista Brasileira de Produtos Agroindustriais, Campina Grande, v.12, n.2, p.115-123, 2010. Disponível: http://www.deag.ufcg.edu.br/rbpa/rev122/Art1222.pdf.

SILVA, R. R.; MONTEIRO, S. S.; ROSA, C. S. Desenvolvimento de biscoitos tipo cookie formulados com amêndoa de pequi (Caryocar brasiliense Camb.) comparados com biscoitos tipo cookie de chocolate. Revista Brasileira de Produtos Agroindustriais, Campina Grande, v.16, n.1, p.77-82, 2014. Disponível: https://www.researchgate.net/publication/277927393_Desenvolvimento de biscoitos tipo cookie formulados com amêndoa de pequi (Caryocar brasiliense Camb) comparados com biscoitos tipo cookie de chocolate. 